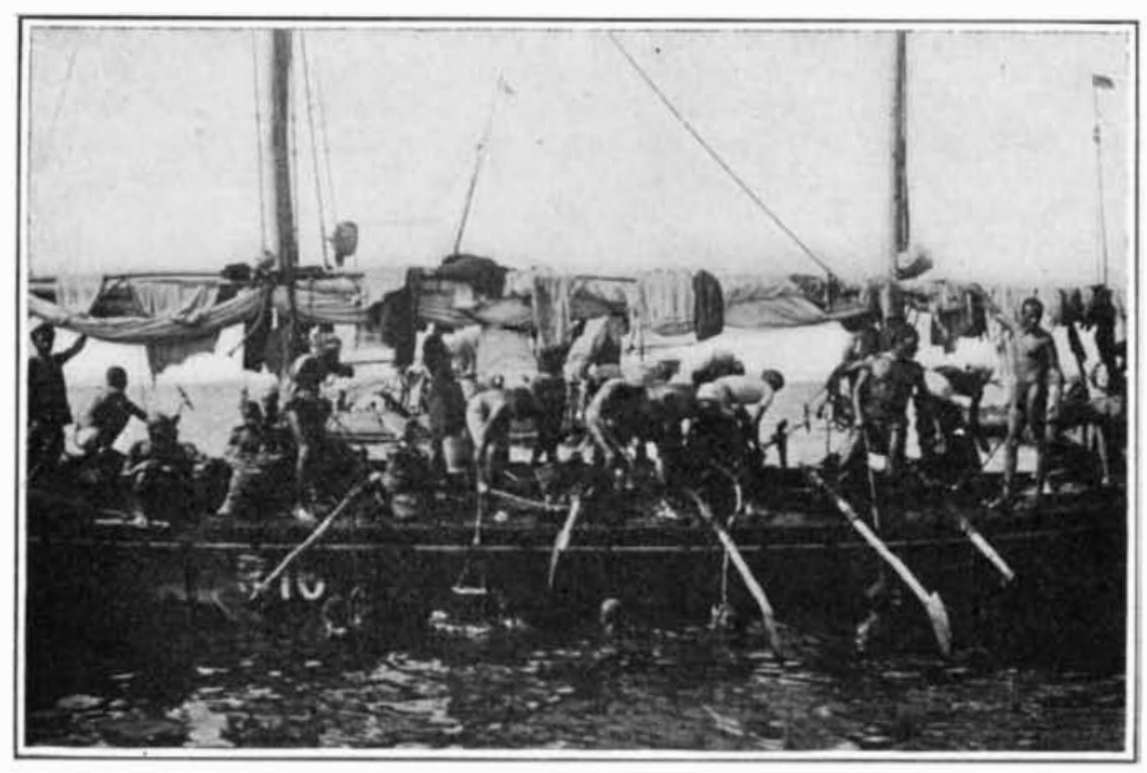

Native pearl fishers at work on a bank.

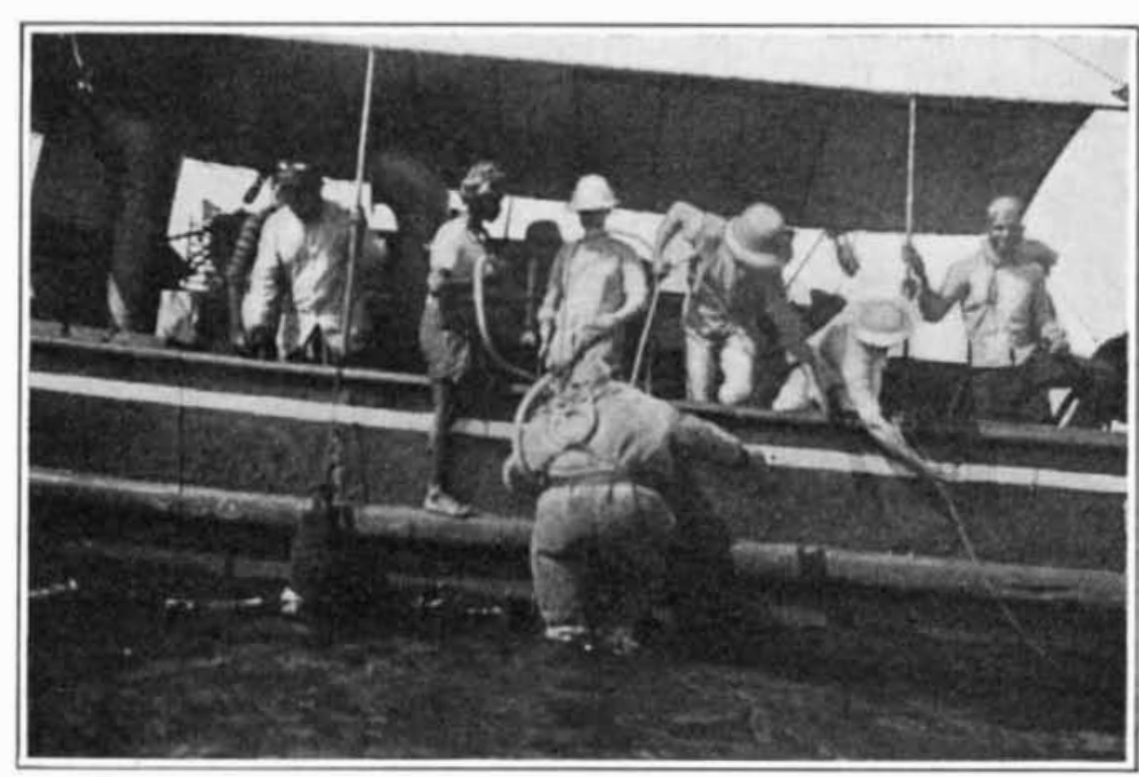

An inspector about to descend in a diving dress.

\title{
The Pearl Fisheries of Ceylon
}

How the Pearl-Bearing Oysters are Gathered by Naked Divers

\author{
By R. I. Geare
}

THE finding of large and valuable pearls has been a matter of deep interest to mankind for centuries. The Ceylonese fisheries, which had been operated at intervals since long before the Christian era, are probably the most ancient of these.fisheries. The most perfect pearl ever discovere in that region was bought in 1633 by the Shah of Persia for about $\$ 51,000$ from an Arab, who brought it from Catifa, a fishery opposite Bhareen in the Persian Gulf. Another magnifcent pearl-a black specimen-was sold to a New York firm not many years ago for about $\$ 25,000$.

The true pearl oyster, known scientifically as Melea grina margaratifera, and belonging to the family Aviculidæ, differs from the edible oyster in having a small "foot" and anterior adductor muscle, a well-developed byssus gland, which secretes a bunch of fibers by which the animal is attache to rock or stone, and a thick "mother-of-pearl" layer to the shell.

The Ceylon fisheries are operated on banks covering an extensive area off the north coast of the island. Tradition has it that King Solomon obtained some of his wonderful pearls from the Ceylon banks; and even the pearls which Cleopatra dissolved and drank are credited with a Ceylonese origin.

The banks most famous in past times lie close to the shore in the Gulf of Mannar, near a place called Marichchukkaddi.

At one time, when Ceylon was under the Tamil power, the pearl fisheries were conducted frequently and successfully. They were watched over by a Tamil princess, who was carried to the end of the Karaittiva Point, and there enthroned until the fishery was over, to prevent robbery on the part of the divers.

One of the earliest mentions of pearl fisheries in Ceylon occurs in the Rajavali chronicle (306 B. C.) where they are spoken of as being located near Colombo; but they were unfortunately destroyed by an inundation from the sea.

During the Portuguese control of the island of Ceylon there is no record of any pearl fishing, but during the 140 years it was occupied by the Dutch there were at least four important fisheries between 1732 and 1749, in the course of which probably not less than a millio dollars' worth of pearls were secured.

During the British occupancy of Ceylon, which still exists, the pearl banks have been under the inspectorship of the "Master Attendant of the port of Colombo," while the government agent of the Northern Province acts as "Official Superintendent."

The oyster beds are formed by an amalgam of coarse granite sand and old oyster shells cemented together with coral lime. Here there is but little movement of the sand, so that the oysters remain easily accessible; but away from the beds the sand, which is loose, is formed into huge waves, which have the effect of covering up and destroying the oysters immediately.

The life of a Ceylon pearl oyster is not more than eight years, and from about its third year it seems to be most productive, both in the number and size of pearls. As a matter of fact very few 3-year oysters contain valuable pearls, but when a bed of oysters is fished just as they are dying off with old age the pearls obtained are liable to be many and large.

True pearls, which are, in fact, the result of a disease sometimes brought about by the introduction into the shell of some foreign body, such as a grain of sand, an undeveloped egg, a parasite, etc., are formed in the tissue of the oyster, and when they reach such a size as to cause great discomfort to the oyster the latter either dies or forces the pearl toward the opening between the valves, where it is retained by an absolutely transparent substance or skin, and here it increases in growth

Owing to the monsoons pearl fishing can be carried on only in March and April. During the preceding fall or early winter (generally in November), the inspector causes some 20,000 oysters to be "lifted," and if the average is satisfactory the fishery is ordered. When the proper time arrives the boats, each containing divers who work five at a time, are rowed or sailed to the banks. Each pair of divers has an attendant known as a "manduck." The boat also contains a "tindal," or representative of the owner of the boat, and a "peon," who represents the interests of the government.

The divers are allowed for payment one third of he oysters taken, while the government auctions of the remainder on the beach the same evening they are caught. The oysters are then placed by the purchasers in "kottus," or inclosures, and are allowed to rot fo eight or ten days in some receptacle-often a wooden canoe-which is covere over to shade the oysters from the sun, but permits filies to obtain free access, as they assist in the process of rotting. Later, the whole mass is washed with clean water, the shells, stones and bysus (or green, string-like substance by which the oyster attaches itself to the rock) are picked out, and the residue placed on long strips of black calico to dry. During the drying process the whole mass is picked over and over again and carefully scrutinized for the smallest pearls.

In classifying the pearls a series of brass cullenders or "baskets" is used. They are about the size of an ash tray, and are provided with holes, which are of ven size in each "basket" The one with the largest ized holes has twenty of them, while others have a many as'several hundred holes each. By this method of sifting, the larger pearls are readily preserved, but the tiny seed pearls are often accidentally left in large numbers near the oyster washing place, and for a long time afterward men and women search the sands for these minute treasures.

Seed pearls, it may be explained, are chiefiy used by Indian princes, being pounded into powder to form "chunam" for betel-chewing, and they are also extensively employed in embroideries and cluster neckaces.

The actual operation of diving for pearl oysters is in this wise: When the divers are ready they climb ove the side of the vessel, place one foot on a large stone, which is held clear of the boat by two poles fastene,

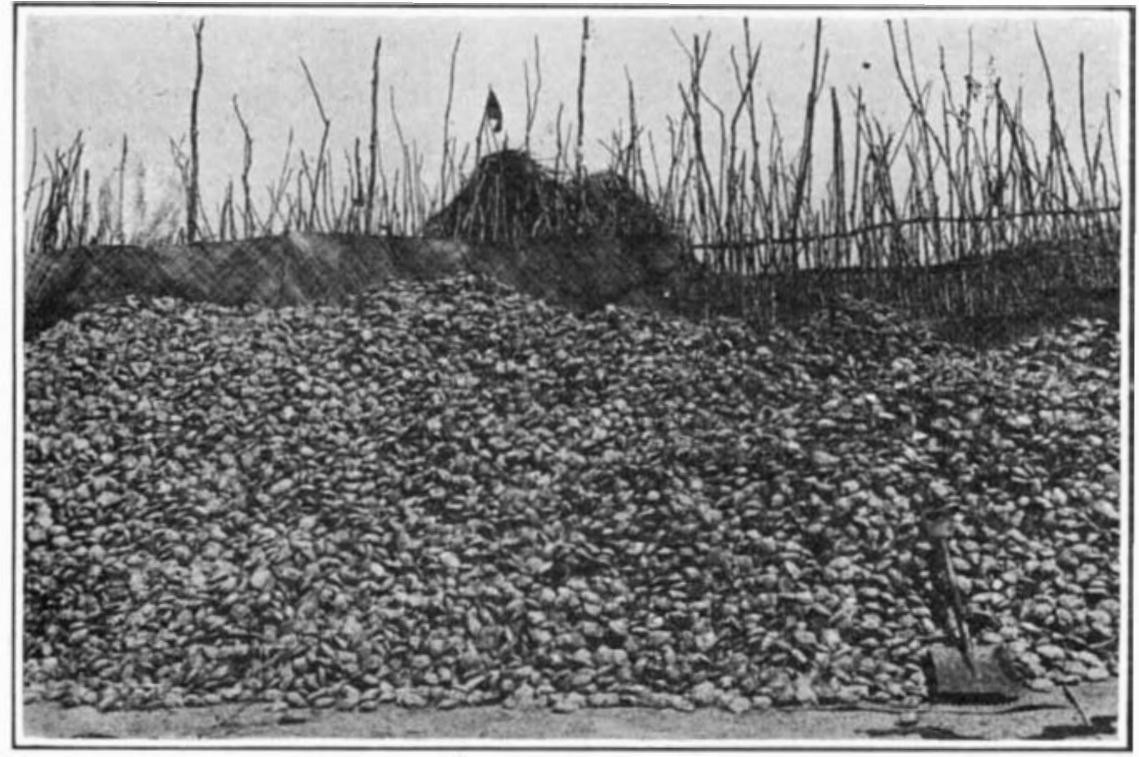

Pearl oysters in a Kottu, or rotting inclosure

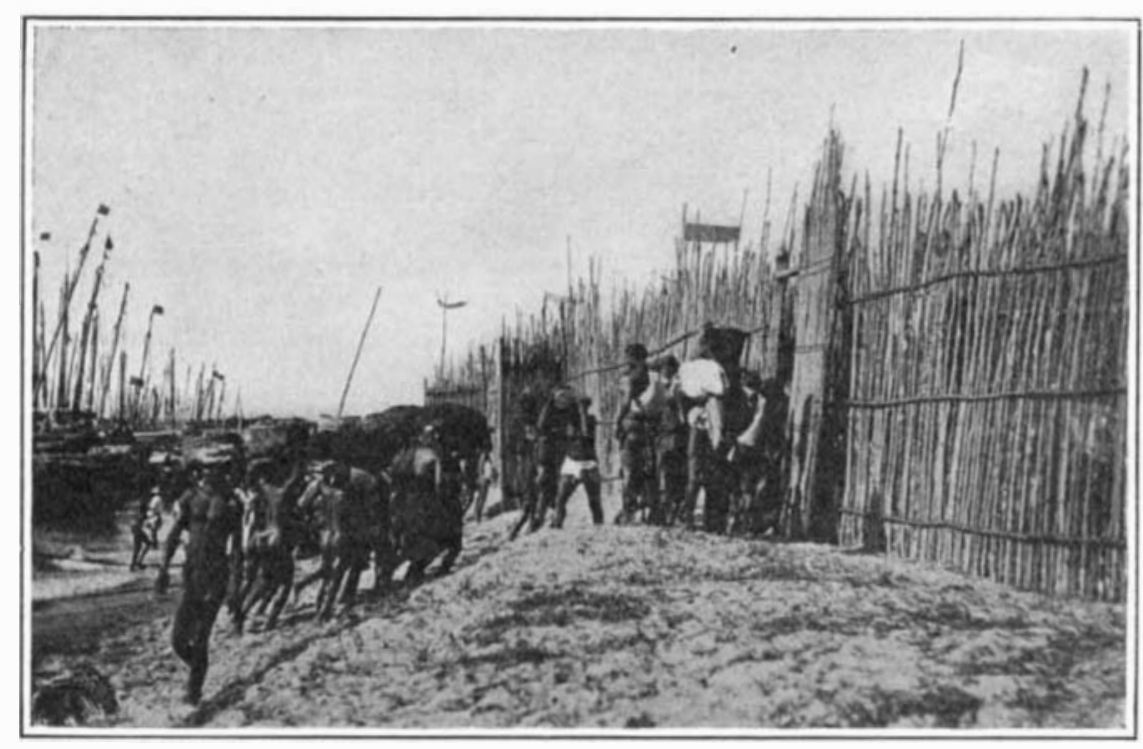

Pearl fishers landing their catch. 
at right angles over the boat's side, and by a third pole which lies parallel to the length of the vessel and is lashed to each end of the other two.

Grasping the rope which is attached to this stone and hitching over his arm the rope attached to the basket in which the diver places his catch, he takes a deep breath, closing his nostrils with his free hand, and slightly raising himself-to add impetus to his descent - gives the signal to the "manduck" to release the rope to which the stone is fastened. On reaching the bottom the diver lets go of the stone, which is then hauled up, so as to be ready for the next descent, and, swimming on the bottom, grasps all the oysters within his reach. When his breath is nearly exhausted, the diver signals to be pulled up with his basket and rises partly by his own initiative. Occasionally the divers are severely stung by jellyfishes, and sometimes they stay down too long and, actuate by avarice or overestimating their 'own strength, are brought up dead. When collecting the oysters they seem to float on the bottom of the sea, with backs arched and heels above their heads, while their long hair waves in a graceful manner and is upheld by the action of the water. A Tamil diver remains below from 50 to 60 seconds, but an Arab can stay down from 80 to 90 seconds.

Diving bells were imported into Ceylon by Sir Edwards Barnes in 1825, but they nor Europeans in a diving d ress can compete with the naked diver.

The catch of one boat for a successful week's fishing should total about 180,000 oysters.

\section{X-Rays and Crystalline Structure}

\section{Discoveries That Assist in the Understanding of Theories of X-Rays and Light}

\section{By Prof. William H. Bragg}

Two years have gone by since Dr. Laue made his surprising discovery of the interference effects accompanying the passage of $\mathrm{X}$-rays through crystals. The pioneer experiment has opened the way for many others, and a very large amount of work, theoretical and practical, has now been done. As the preliminary exploration of the new country has proceeded, our first extimate of its resources has grown continuously; we estimate of its resources has grown continuously; we
have learned many things which help us to a better understanding of phenomena already familiar, and we have seen avenues of inquiry open out before us which as yet there has been little time to follow. The work is full of opportunities for exact quantitative measurements, where precision is sure to bring its due reward. There is enough work in sight to absorb the energies of many experimenters, and there is sure to be far more than we can see. When we consider the wideness of the new field, the quality and quantity of the work to be done in it, and the importance of the issues, we are scarcely guilty of ever-statement if we say that Laue's experiment has le to the development of a new science. The experiment itself, to put it very briefiy, constitutes a proof that X-rays consist of extremely short ether waves. In order to appreciate the value of this demonstration, we must bear in mind the present conditions of our knowledge of the laws of radiation in general. Let us consider very shortly how the whole matter stood when the new work was begun.

When X-rays were first discovere eighteen years ago it was soon pointed out that they might consist of electro-magnetic disturbance of the ether analogous to those supposed to constitute light. It was true that the new rays seemed to be incapable of refiection, refrac tion, diffraction and interference, which were familia optical phenomena. But it was pointed out by Schuster $^{1}$ that these defects could be explained as natural consequences of an extremely small wave-length. The positive evidence consisted mainly in the knowledge that the impact of the electrons on the anti-cathode of the X-ray bulb ought to be the occasion of electromagnetic waves of some sort, and in the discovery by Barkla that the X-rays could be polarized, which las is a property also of light.

As experimental evidence accumulated, a number of results were found which the electro-magnetic theory was unable to explain, at least in a direct and simple manner. They were mainly concerned with the transference of energy from place to place. In some way or other the swiftly moving electron of the X-ray bulb transfers the swiftly moving electron of the X-ray bulb transfers
its energy to the X-ray, and the X-ray in its turn communicates approximately the same quantity of energy to the electron which originates from matter lying i the track of the X-ray, and which is apparently the direct cause of all X-ray effects. Experiment seemed to indicate that X-ray energy travele as a stream of separate entities or quanta, the energy of the quantum differing according to the quality of the X-ray. It looked at one time as if it might be the simplest plan to deny the identity in nature of X-rays and light, to describe the former as a corpuscular radiation and th latter as a wave motion. Otherwise, it seemed that the electro-magnetic hypothesis would be torn to pieces in the effort to hold all the facts together.

But it appeared on a close examination of light phenomena also, though in much less obvious fashion, that the very same effects occurred which in the case of X-rays were so difficult to explain from an orthodox point of view. In the end it became less difficult to deny the completeness of the orthodox theory than the identity in nature of light and X-rays. Modern work on the distribution of energy in the spectrum, and the dependence of specific hes $t$ upon temperature, has also led independently to the same point of view. It has been urged with great force by Planck, Einstein, and others

* Read before the Royal Institution of Great Britain, June 5th, 1914.

vature, January 23rd, 1896 that radiated energy is actually transferred in definite units or quanta, and not continuously; as if we had to conceive of atoms of energy as well as of atoms of matter. Let it be admitted at once that the quantum theory and the orthodox theory appear to stand in irreconcilable opposition. Each by itself correlates great series of facts; but they do not correlate the same series. In some way or other the greater theory must be found, of which each is a partial expression.

The new discovery does not solve our difficulty at once, but it does two very important things. In the first place, it shows that the X-rays and light are identical in nature; in fact, it removes every difference except in respect to wave-length. The question as to the exact place where the difficulty lies is decided for us; we are set the task of discovering how a continuous wave motion, in a continuous medium, can be reconciled with discontinuous transferences of radiation energy. Some solution there must be to this problem. The second important thing is that the new methods will surely help us on the way to find that solution. We can now examine the X-rays as critically as we have been able to study light, by means of the spectrometer. The wavelength of the X-ray has emerged as a measurable quantity. The complete range of electro-magnetic radiations now lies before us. At one end are the long waves of wireless telegraphy, in the middle are first the waves of the infra-red detected by their heating effects, then the light waves, and then the short waves of the ultraviolet. At the other end are the extremely short waves that belong to X-radiation. In the comparative study of the properties of radiation over this very wide range we must surely find the answer to the greatest question of modern physics.

So much for the general question. Let us now consider the procedure of the new investigations, and afterwards one or two applications to special lines of inquiry.

The experiment due to Laue and his collaborators Friedrich and Knipping has already been described in this lecture room and is now well known. A fine pencil of X-rays passes through a thin crystal slip and imof X-rays passes through a thin crystal slip and im-
presses itself on a photographic plate. Round the central spot are found a large number of other spots, arrange in a symmetrical fashion, their arrangement clearly depending on the crystal structure. Laue had anticipate some such effect as the result of diffraction by the atoms of the crystal. His mathematical analysis is too complicated to be described now, and indeed it is not in any circumstances easy to handle. It will be better to pass on at once to a very simple method of apprehending the effect which was put forward soon after the publication of Laue's first results. I must run the risk of seeming to be partial if I point out the importance of this advance, which was made by my son X-ray spectra Bragg. All the recent investlgations and of molecular motions which have been carried out since then have been rendered possible by the easy grasp since then have been rendered possible by the easy grasp
of the subject which resulte from the simpler conception.

Let us imagine that a succession of waves constituting X-radiation falls upon a plane containing atoms, and that each atom is the cause of a secondary wavelet. In a well known manner, the secondary wavelets link themselves together and form a refiected wave. Just so a sound wave may be reflected by a row of palings, and a sound wave may be reflected by a row of palings, and
very short sound waves by the fibers of a sheet of very shorlin.

Suppose a second plane of atoms to lie behind the first and to be parallel to it. The primary wave, weakene somewhat by passing through the first plane, is again partially refiected by the second. When the two reflected pencils join it will be of great importance whether they fit crest to crest and hollow to hollow, or whether they tend to destroy each other's effect. If more reflecting planes are supposed, the importance of a good fit becomes greater and greater. If the number is very large, then, as happens in many parallel cases in optics, the refiected waves practically annul each other unless the fit is perfect.

It is easily seen that the question of fit depends on how much distance a wave refiected at one plane loses in comparison with the wave which was reflected at the preceding plane: the fit will be perfect if the loss amounts to one, two, three, or more wave-lengths exactly. In its turn the distance lost depends on the spacing of the planes, that is to say, the distance from plane to plane, on the wave-length, and on the angle a which the rays meet the set of planes.

The question is formally not a new one. Many years ago Lord Rayleigh discussed it in this room, illustrating his point by aid of a set of muslin sheets stretched on parallel frames. The short sound waves of a high pitched bird call were refiected from the set of frame and affected a sensitive fiame; and he showed how the spacing of the planes must be carefully adjusted to the proper value in relation to the length of wave and the angle of incidence. Rayleigh used the illustration to explain the beautiful color of chlorate of potash crystals. He ascribed them to the refiection of light by a series of parallel and regularly spaced twinning planes within the crystal, the distance between successive planes bearing, roughly, the same proportion to the ength of the reflected wave of light at the distance between the muslin sheets to the length of the wave of ound.

present phenomenon is exactly the same thing on minute scale; thousands of times smaller than in the case of light; and many millions of times smaller than in the case of sound.

By the kindness of Prof. R. W. Wood I am able to how you some fine examples of the chlorate of potash crystals. If white light is allowed to fall upon one of them, the whole of it is not reflected. Only that part is refiected which has a definite wave-length or some thing very near to it, and the refiected ray is therefore highly colored. The wave-length is defined by the relation already referred to. If the angle of incidence is altered, the wave-length which can be refiected is altered, and so the color changes.

It is not difficult to see the analogy between these cases and the reflection of X-rays by a crystal. Suppose, for example, that a pencil of homogeneous X-ray meets the cube face of such a crystal as rocksalt. Th atoms of the crystal can be taken to be arranged in planes parallel to that face, and regularly spaced. If the rays meet the face at the proper angle, and only at the proper angle, there is a reflected pencil. It is to be remembere that the refiection is caused by the joint action of a series of planes, which, in this case, are parallel to the face; it is not a reflection by the face itself. The face need not even be cut truly; it may be unpolished or deliberately, roughened. The refiection takes place in the body of the crystal, and the condition of the surface is of little account.

The allotment of the atoms to a series of planes parallel to the surface is not, of course, the only one possible. For example, in the case of a cubic crystal, parallel planes containing all the atoms of the crysta may also be drawn perpendicular to a face diagonal of the cube, or to a cube diagonal, or in many other ways. We may cut the crystal so as to show a face parallel to any series, and then place the crystal so that reflection occurs, but the angle of incidence will be different in each case since the spacings are different. It is not each case since the spacings are different. It is not ware-length, spacing, and angle between ray and plane are rightly adjusted to each other, reflection will take place in the crystal independently of any surface ar rangement.

This is the "refiection" method of explaining the Laue photograph. W. L. Bragg showed in the first place that it was legitimate, and in the second, that it was able to explain in the position of all the spots which Laue found upon his photographs. The different spots are 